\title{
9
}

\section{A PROGRAMME THEORY APPROACH TO EVALUATING NORMATIVE ENVIRONMENTAL INTERVENTIONS}

\author{
Segbedzi Norgbey and Michael Spilsbury
}

\section{Introduction}

In the lead-up to Rio+20, many countries commented on the 'Institutional Framework for Sustainable Development' and articulated the need to promote a better balance among its environmental, social and economic pillars. Despite the difficulties experienced in finding common agreement on how to take this idea forward in practical terms, it is now well accepted that there needs to be a greater focus placed on the interlinkages among these pillars in responses to global sustainable development challenges.

Global governance frameworks for environmental issues are fragmented. The last 40 years have seen a proliferation of multilateral environmental agreements. Individually, each has been a step forward in strengthening governance responses to environmental concerns, yet collectively, their provisions have lacked coherence. As such, country efforts to comply with an ever-increasing number of conventions and their related requirements are unlikely to lead to optimal sustainable development solutions - resources will continue to be allocated to piecemeal responses. Simplifying global governance structures will present opportunities to bring about a greater integration of environmental, social and economic objectives in policymaking at the country level in order to move beyond sector-specific responses (i.e. the strengthening of international environmental governance).

A significant portion of the United Nations Environment Programme's (UNEP) work is geared towards influencing these international and national policy-making processes; the agency regards environmental sustainability as a key foundation upon which sustainable development rests. This work is often described as being largely normative in nature.

In this chapter, the authors argue that there are no clear differences between the methods used to evaluate normative aspects of development work and the methods 
used to evaluate more operational (or 'on the ground') activities. Any perceived differences are in the relative lengths and complexities of the causal chains leading from the intervention to the desired results and impacts.

The arguments articulated in this chapter are founded on theory-based approaches to evaluating development interventions. They are based on the realization that development interventions, whether designed with clear intervention logic or haphazardly/opportunistically formulated, have an underlying intent - to produce change from one state or condition to another. Thus, development interventions are embodiments of theories. ${ }^{1}$ Inherent in this assertion is the idea that not only is there a clear underlying logic or theory on which the interventions (new programmes or policy) are based, but also that given stated or unstated assumptions the interventions' outcomes can be traced back to the activities undertaken. Indeed, in the United Nations (UN) system (as well as in many international development agencies), the most commonly used approach to planning development interventions is the logical framework matrix, which has the intentionality of proposed interventions at its core.

If one views development interventions as a set of activities with causal intent, it is possible to deploy theory-based approaches to explore the intended changes and determine whether the interventions have, indeed, produced the expected changes (and explore whether interventions yielded unexpected changes). This chapter describes approaches to evaluating the environmental aspects of international development with particular reference to UNEP work in general, and its normative aspects in particular.

\section{The nature of normative environmental work}

The UN defines normative work to include support to the development of norms and standards in conventions, declarations, regulatory frameworks, agreements, guidelines, codes of practice and other standard setting instruments, at global, regional and national levels. Normative work may also include support to the implementation of these instruments at the policy level, that is, their integration into legislation, policies and development plans (UNEG 2014).

In order to effectively address environmental issues, governments and institutions need to understand, evaluate, predict and respond to emerging needs. Providing information for decision-making is a key role performed by UNEP in international environmental governance processes. As part of its mandate to 'keep the world environment situation under review', UNEP places considerable emphasis on supporting and building assessment capacity at the global, regional and national levels. Developing policy guidelines and providing support to establishing global and regional environmental agreements is one of the key means by which UNEP catalyses action among governments.

In order to achieve this goal, UNEP provides support to the development of institutional and legal frameworks, especially at the national level, through efforts that include building capacities in the fields of institution-building and environmental law. UNEP's activities in this area also include enhancing the ability of developing country governments and countries with economies in transition to participate, in 
a meaningful way, in the negotiation of multilateral environmental agreements and in meeting their obligations under these agreements. UNEP provides intellectual leadership and acts as a catalyst for environmental action by disseminating environmental information and promoting public participation through the forging of partnerships with non-governmental organizations, the private sector and civil society groups.

The 2010-2013 UNEP Medium Term Strategy states the organization's mandate as comprising five overall, interrelated areas:

1. Keeping the world environmental situation under review;

2. Catalysing and promoting international cooperation and action;

3. Providing policy advice and early warning information, based upon sound science and assessments;

4. Facilitating the development, implementation and evolution of norms and standards and developing coherent inter-linkages among international environmental conventions; and

5. Strengthening technology support and capacity in line with country needs and priorities.

The organization's scope of work is broad, extensive and predominantly normative. It relates to the development of guidelines, norms and standards; to the support to conventions, international agreements and policy development processes; to the support to the development of legislative frameworks, capacity building and technology support; and to the assessment of global environmental trends.

Even when UNEP project and programme activities are implemented 'on the ground', the focus has been predominantly normative; pilot and demonstration sites are often intended to feed back into broader policy formulation and improvement. Project activities often include developing norms, standards, strategic action plans, policy options and strategies to address the environmental dimensions of poverty alleviation. Interventions frequently aim at strengthening communication, information and research networks on environmental issues; promoting cleaner production and sustainable resource use through developing guidelines and policies; and demonstrating and promoting the use of improved technologies as practical approaches for policy improvement or development. UNEP interventions frequently feature mainstreaming environmental considerations (within and across various sectoral policies, legislation, programmes and projects), and strengthening institutional capacities for disaster and conflict prevention and preparedness in high-risk areas.

\section{Evaluation approaches}

\section{Discussion of evaluation methods}

Development evaluation literature is replete with categorizations and classifications of approaches to evaluating international development interventions. Evaluations can be classified as deductive or inductive. 
Deductive methods draw out the intervention's implications and assess evidence that the intervention's design achieved its anticipated outcomes. Deductive approaches often use theory-based methods that use logic models to describe the intervention logic. Commonly used terms and approaches include 'Theory of Change', 'causal pathway analysis', 'programme theory', 'impact pathway analysis', 'outcome mapping, 'results chains' and 'systemic evaluation' (Chen 2005; Bamberger, Rugh and Mabry 2006; GIZ 2011). Theory-based methods are not new; indeed, they are at the core of the long-accepted logical framework approach. However, in contrast to a logical framework, a full theory of change allows consideration of multiple pathways and better captures the actions required and possible risks at various stages along the causal pathways from activities towards intended results.

In contrast, inductive methods involve qualitative analysis oriented towards explorations, discovery and inductive logic (Patton 1987). These evaluation approaches are inductive to the extent that the evaluator makes no assumptions about prior intentions, except at the broad level of general goals. When an inductive approach is used, meaning is constructed after the event out of reflections on past events, including changes that may or may not be seen as achievements or that may or may not have been anticipated (Davies 2003). The approach begins with the evaluator making specific observations and builds towards general patterns. The nature and dimension of analysis required are often derived from observation as the evaluator gains a greater understanding of existing programmes or projects (Patton 1987; Bamberger, Rugh and Mabry 2006; Thomas 2006).

Patton (1987) notes two other ways that evaluation approaches can be inductive. Within a programme, an approach can be inductive if it involves exploring programme participants' and stakeholders' individual experiences through structured or unstructured interviews and questionnaires. Among programmes, the inductive approach looks for the characteristics of each programme that make them unique. Goal-free evaluation is the most commonly used inductive approach.

In goal-free methods, the evaluator starts with the changes that are evident and investigates whether the programme being evaluated has played any substantive role in the observed change. Approaches based on stakeholder participation are built on the principle that stakeholders should be involved in all stages of evaluation, including determining objectives and impacts, identifying and selecting indicators and participating in data collection and analysis (Leeuw and Vaessen 2009).

Evaluations have been classified as theory-driven and atheoretical. Theorydriven approaches formulate programme elements, rationale and causal linkages. The atheoretical approach to evaluation, at the extreme end, is characterized by 'a step-by-step cookbook method of doing evaluations' (Chen 1990: 18). The atheoretical approach tends to focus on the relationship between inputs and effects (black box evaluations) without taking into account the transformational processes that are inherent in the programmes being evaluated. Claims of success based on such input-effect models generate conclusions about programmes that policy makers may find difficult to apply. For example, if a simple input/output evaluation shows that eliminating chlorofluorocarbons will reduce climate change without providing 
information on the underlying mechanisms and processes, the consequences of the policy prescriptions on the economy and environment will not be known and policy makers will have extreme difficulty in designing policy options.

Furthermore, conclusions from input-effect models that indicate programme failure may be misleading. It is possible that models or evaluations that follow this approach may not explain which was flawed - the logic on which the intervention was based or the processes used to implement the intervention. In other words, such evaluative approaches provide limited information to assist managers to improve programmes.

In practice, evaluations are neither wholly inductive nor deductive. Some evaluation questions are left for inductive analysis based on direct observation; others are determined deductively. Patton (1987: 16) argues that there is often a 'flow from inductive approaches to find out what the important questions and variables are (exploratory work), to deductive hypothesis-testing aimed at confirming exploratory findings'. Similarly, the methods evaluations apply are seldom wholly naturalistic or experimental, theoretical or atheoretical.

Evaluation methods have evolved significantly beyond simple black box approaches, and a consensus has emerged among evaluators that evaluations must deal with multiple values in which different methods can be deployed that are tailored to unique situations. Depending on the specific questions or objectives of a given evaluation, some methods have advantages over others. Particular methods or perspectives may complement one another in providing a more complete picture (Leeuw and Vaessen 2009).

Impact evaluations are 'focused on quantifying the lasting and significant changes that occurred in the short or long term, direct or indirect, produced by an intervention or a body of work, or to which the same has contributed'. ${ }^{2}$ Impact evaluations attempt to establish whether an intervention has caused the observed effects and explain how the effects were caused to satisfy the operational improvement/learning objective of evaluation. Establishing causation without explanation of the processes limits the utility of evaluation findings; a strong theoretical underpinning is essential both for intervention design and for evaluation.

Although not routinely undertaken, impact evaluations are in great demand by the donor community. The primary reason for the increased demand is that many outside of development agencies believe that the results achieved from the expenditure of international development resources have been poor or not adequately documented. Changes expected from development interventions are not evident after the interventions have come to an end, and donors wonder if the interventions made any difference (Leeuw and Vaessen 2009). Impact evaluations provide the evidence to demonstrate that the interventions have 'made a difference' and often quantify how large the impacts are. However, evaluating impacts is a complex and costly exercise, often fraught with methodological difficulties and therefore undertaken selectively. 


\section{Theory-based approaches: causal pathways - theory of change}

Environment and sustainable development issues are complex and deal with overlapping and interrelated biophysical, economic, social and political systems, often at multiple scales. Designing and evaluating interventions must both define and bound the unit of intervention and the evaluative analysis. Models, as simplified representations of reality, are needed to focus on interventions' design and/or to provide a framework for the evaluation. Causal pathway analysis or Theories of Change provide a means for this.

A Theory of Change depicts and describes (i.e. provides a simple model of the causal processes through which changes occur as a result of interventions. There are many published resources that provide guidance on the development and use of theory of change approaches and logic models (Bamberger et al. 2004; Chen 2005; University of Kansas 2013). Theories of change or causal pathway diagrams should be regarded as conceptual frameworks that summarize sequences of planned, desired or observed change. As such, they can be usefully applied to aid project design, monitoring and evaluation.

Figure 9.1 shows a graphical representation of generic set of causal pathways for an intervention. The pathways are comprised of the standard result levels used in project logical frameworks: outputs, outcomes and objectives. ${ }^{3}$ The pathways represent causal relationships and, when elaborated in detail, help identify or clarify

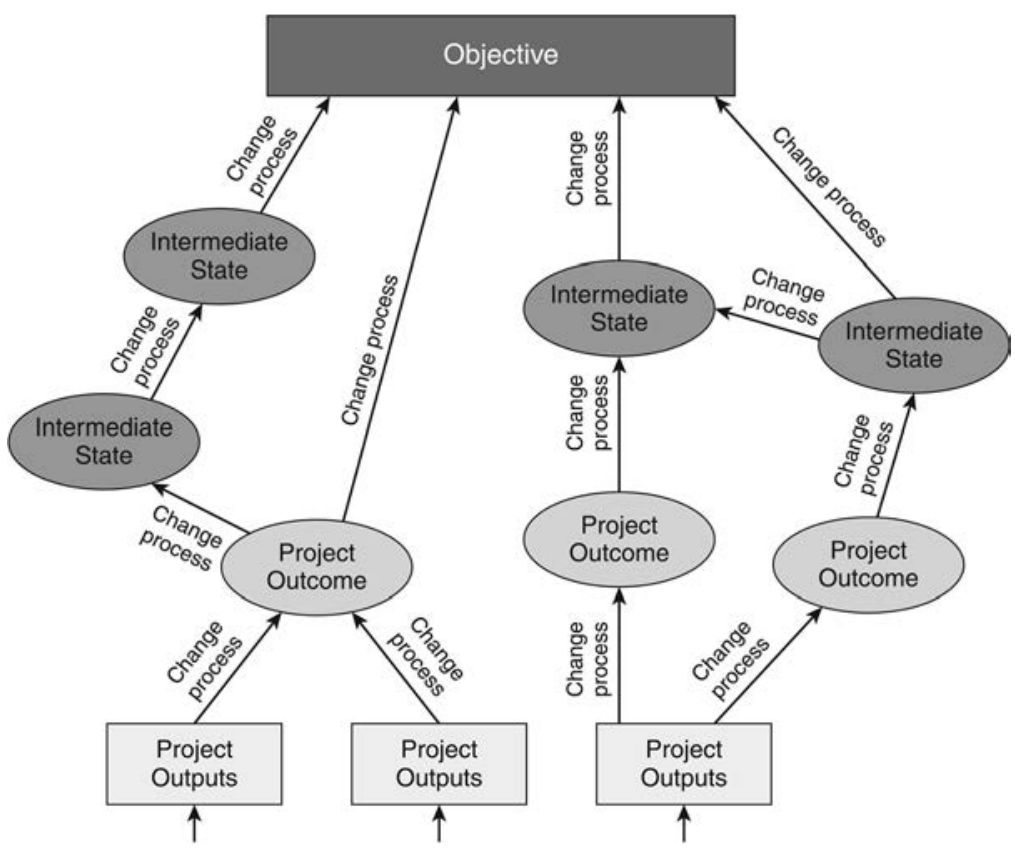

FIGURE 9.1 A Set of Generic Results Chains, which can also be Termed 'Causal Pathways', 'Impact Pathways' or a 'Theory of Change' 
the assumptions in the intervention logic of a project or programme. From the schematic diagram, it can be observed that more than one output and change process may be required to achieve a certain outcome or, alternatively, one single output may be required for more than one outcome (via different change processes). In addition, there may be further outcome stages (termed 'intermediate states' in the diagram) between the immediate project outcome and the desired objective. The figure shows six different pathways from the outputs to the objective, but activities to produce outputs and promote/foster change processes are not shown. When specified with additional detail, in particular including the key users of outputs, description of the change processes (represented by the arrows in Figure 9.1) including externalities (assumptions), 'impact drivers' and details of performance indicators (for either processes or result levels or both), causal pathway analysis can be invaluable as a tool for both project/programme planning and for evaluation. Figure 9.2 takes one of the six pathways from Figure 9.1 and shows a single generic causal pathway with impact drivers and assumptions.

It should be stressed that the activities in a results-oriented intervention are not restricted to a level prior to or below outputs as they are often presented in a logical framework. Rather, activities also feature in the processes that link outputs to outcomes and those outcomes to higher-level results. Intervention designs should describe the activities needed to produce the outputs and those activities needed to ensure that the outputs will lead to outcomes and higher-level results. Project and programme activities should therefore feature in or complement the impact drivers (see Box 9.1).

Similarly, evaluation considers the observed changes and attempts to establish whether the intervention played a role in causing them. There are often several pathways that lead to results in a single project or programme intervention, and though multiple pathways can be captured in logical frameworks they are often more difficult to interpret in that form. Logical frameworks seldom provide sufficient detail in relation to the change processes that link one result level to the next. Pathways that do not form part of the intervention do not readily feature in logical frameworks. In contrast, casual pathway analysis can incorporate pathways (change processes) that are external to the intervention.

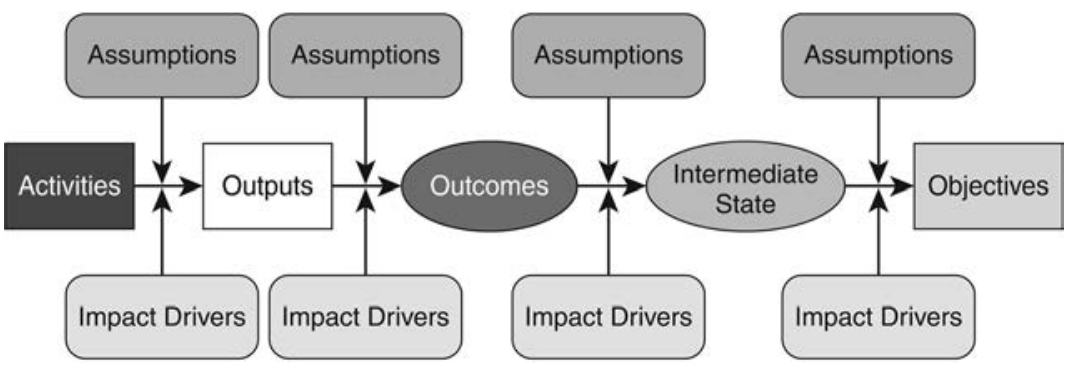

FIGURE 9.2 A Schematic Single 'Impact Pathway' Showing Intermediate States, Assumptions and Impact Drivers 


\section{BOX 9.1 IMPACT DRIVERS AND ASSUMPTIONS}

Impact drivers are the significant factors that, if present, are expected to contribute to realizing the intended impacts and can be influenced by the project, by project partners and by stakeholders. They are often referred to as a project's critical success factors.

Assumptions are the significant factors that, if present, are expected to contribute to realizing higher-level results but are largely beyond the control of the project and its partners and stakeholders. The likelihood that the assumptions will not hold is the risk of not achieving results.

Impact drivers and assumptions are often key factors affecting project sustainability.

\section{Does the linear nature of Theory of Change constrain its validity and application?}

A common criticism of both Logical Frameworks and Theory of Change logic models is that they assume linear cause and effect relationships, which limits their utility and validity (Cooperative for Assistance and Relief Everywhere [CARE] 2012). Critics point out that the majority of real-life development interventions with environmental dimensions are complex; there are many interrelated and interacting factors with multiple and often nested feedback loops that involve non-linear relationships that, as such, are not scalable (Mayne and Stern et al. 2012; Vogel 2012a). It is commonly argued that linear models are inappropriate in such situations.

However, all models are simplified representations of reality, with the utility of any model being highly dependent upon its purpose. If any given change process is studied in more detail, it may be found to be highly complex with multiple actors and external factors affecting the change from one level to the next and with feedback relationships between levels. This reality does not invalidate the original Theory of Change, but merely highlights that it is a simplified representation of reality. Similarly, it does not imply that an evaluation using a Theory of Change approach has adopted the assumption that all the change processes are linear. 'The logical sequencing aspect often means that people mistakenly interpret theory of change as a linear sequence of change. Building development impact is not a linear process' (Vogel 2012b: 14).

This discussion also highlights the trade-offs between presenting too fine a level of detail and oversimplifying causal pathways within a theory of change. When too much detail is presented, the big picture can get lost in the complexity of multiple interrelationships. If oversimplified, however, clusters of outputs and outcomes may end up being lumped together and important interconnections and change processes could be overlooked. 
To illustrate the similarities and differences between normative work and more direct forms of intervention, consider the following example: an intervention's desired results are defined in terms of quantifiable changes to a specific measure of environmental status (e.g. reduction in greenhouse gas emissions). An intervention that directly affects that environmental status is likely to be readily planned, monitored and evaluated. Another intervention that aims to achieve the same change in environmental status, but does so more indirectly via, say, a policy change process, followed by formalization of regulations and some form of enforcement 'on the ground', is relatively more challenging to plan, monitor and eventually evaluate because there would be several change processes each with associated actors and factors to consider. The number of steps in the causal chain between the initial interventions and the desired end result of changed environmental status would be quite different. A large portion of UNEP work is normative in nature and is akin to this latter situation. It is imperative, therefore, that the multiple, often long and indirect, causal pathways for interventions are clearly articulated at both project and programmatic levels.

This guides realistic intervention design, effective implementation and facilitates robust evaluation. But why would UNEP focus on normative work if the causal pathways to results on the ground are indirect? Beyond the fact that such work is a key part of the mandate of the organization, it is often the case that more direct pathways to environmental benefits operate at smaller scales. For example, an intervention to improve forest management is unlikely to have the resources to be able to engage each and every forest manager in a country or continent, whereas normative work on forest management standards and regulation processes (such as certification) can change the way legal and regulatory systems function, and these, in turn, can have downstream effects at much larger scales (albeit indirectly).

\section{Application of the Theory of Change approach to evaluating normative environmental projects and programmes}

This section gives a brief overview of the use of Theory of Change/causal pathway analysis in the evaluation of different types of environmental interventions at UNEP. Examples are chosen to highlight trends and lessons.

\section{The 'Synergies Decisions' of the Stockholm, Basel and Rotterdam conventions}

The Decisions (BC.Ex-1/1, RC.Ex-1/1 and SC.Ex-1/1; the... 'omnibus decisions'), were adopted by the Conferences of the Parties to the Basel, Rotterdam and Stockholm Conventions, respectively, at their simultaneous extraordinary meetings in February 2010. Parties decided that they would review the arrangements adopted pursuant to the 'Synergies Decisions', ${ }^{4}$ in particular actions taken by the Secretariats of the Convention to merge and conduct joint activities, joint managerial functions 
and joint services in order to determine how far they had contributed to achieving the following objectives:

1. Strengthening of the implementation of the three Conventions at the national, regional and global levels;

2. Promoting coherent policy guidance;

3. Reducing administrative burdens;

4. Maximizing the effective and efficient use of resources at all levels; and

5. Protecting human health and the environment for the promotion of sustainable development.

The decisions further called upon the Executive Director of UNEP in consultations with the Director General of Food and Agriculture Organization of the United Nations to undertake an independent evaluation and to prepare reports of the evaluation for consideration by the Conferences of the Parties. The evaluation was to focus primarily on the extent to which the synergies process among the chemicals and waste-related conventions has contributed to improving cooperation and coordination at the global, regional and national levels. A Theory of Change (Figure 9.3) was developed prior to initiating the main data-gathering phase of the evaluation from a desk review of convention documents that outlined the aims of the 'Synergies Decisions'. The Theory of Change sets out the causal intent of the synergies decisions and provides a conceptual framework for the evaluation's implementation phase, guiding the data collection necessary for assessing performance indicators. The Theory of Change framework was used to structure interview questions with key stakeholders (e.g. Secretariat Staff and Parties to the Convention), which aided in identifying assumptions and threats that were key to assessing the likelihood of contributions being made to higher level objectives.

Assumptions were identified as the following:

1. Leadership is actively committed to the synergies process: The synergies process involves merging and restructuring the Convention Secretariats into one cohesive team serving all three Conventions, particularly on substantive/technical activities. This requires leadership commitment to the process at the highest level (Executive Secretary) and mid-tier management buy-in to the process of change management and joint-delivery of services to Parties;

2. Accountability and incentive structures are in place to support synergies: Responsibilities and roles are structurally and individually aligned to carry out synergies process and to support teamwork within the restructured secretariat (e.g. job descriptions, operating procedures, functions and processes for teams and clear reporting lines). Appropriate incentives (rewards and sanctions) are in place to underpin delivery of services internally and to Parties;

3. Synergies restructuring is accepted and supported by all staff: The synergies process and actions need to be accepted and supported by all staff and at all levels of the secretariat organization to be successful; 


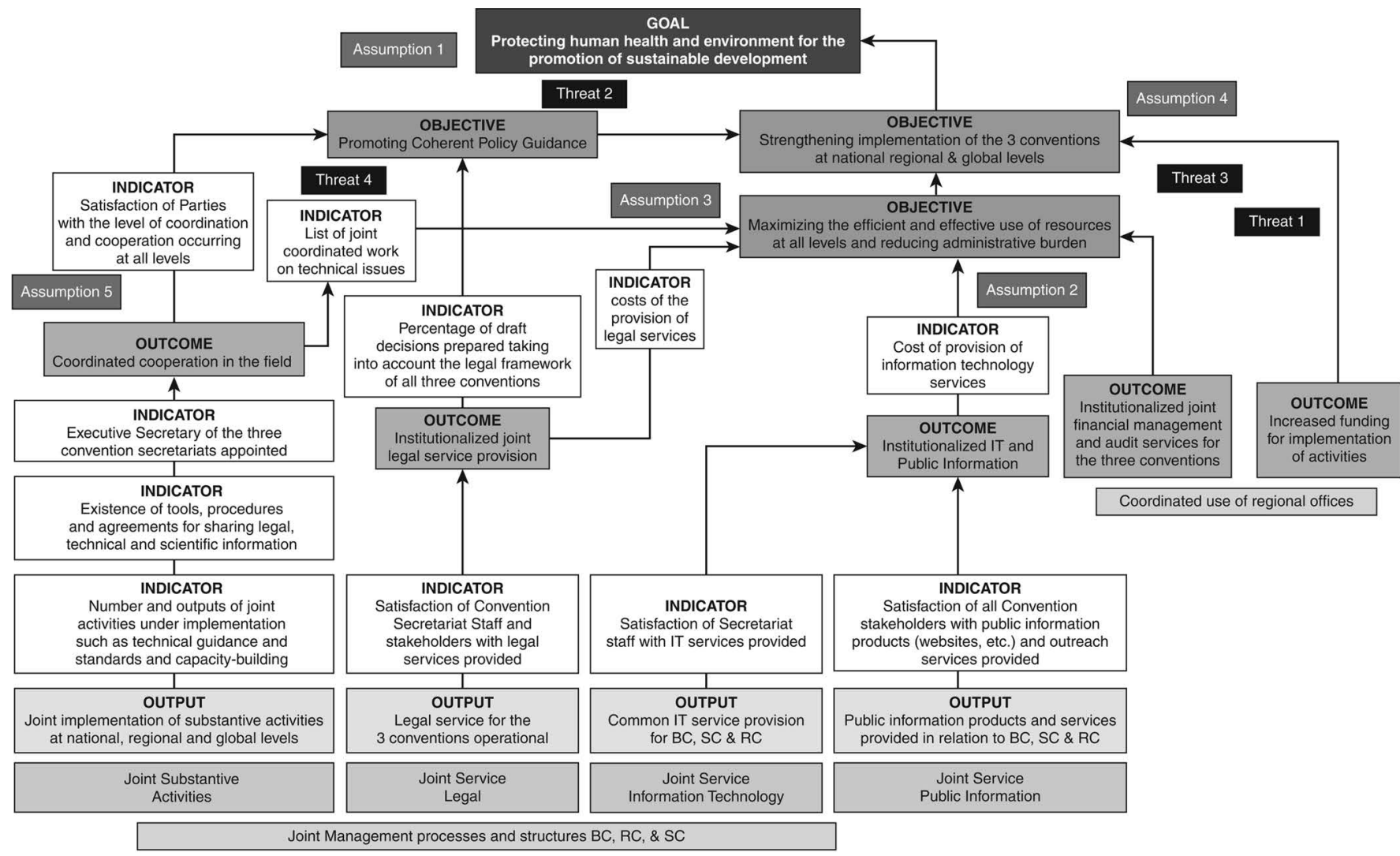

FIGURE 9.3 'Synergies Decisions'Theory of Change (Shown in Part) 
4. Synergies restructuring is cost-neutral and will lead to improved efficiency in implementing the Conventions: The restructuring and merging of the Secretariats (while preserving the legal autonomy of each Convention) and delivery of joint services and substantive activities to Parties will lead to improved efficiency; and

5. Parties are supportive of synergies and carry out the necessary institutional and organizational changes at the national level to promote cooperation and coordination: For the strengthened implementation of the three Conventions and progress towards protecting human health and the environment, it is assumed that Parties will support the synergies process and pursuant actions and take actions at the national level (supported by the Secretariat/UN agencies and other relevant bodies). This will include, inter alia, improved systemic and institutional capacities to improve enforcement of the three Conventions, inter-ministerial coordination (including cooperation between focal points) ${ }^{5}$ and bringing responsibilities for implementation under one ministry (e.g. one focal point for all chemicals Conventions).

Threats to the achievement of outcomes were identified as the following:

1. Cost of synergistic actions rise, leading to decreases in party interest and support: If Assumption 4 (cost neutrality and improved efficiencies) does not hold, then Parties may decide to abandon or limit the synergies process;

2. Potential conflicts between managers, leading to poor delivery of services: Managers may have conflicts over human and financial resources if managerial controls, responsibilities and roles lack clarity within the new matrix structure; ${ }^{6}$

3. No increases in funding for implementation of activities to support the strengthening of the Conventions: A lack of financial support is likely to be a significant threat to the realization of synergies in terms of delivery of substantive activities by the secretariat and implementation of synergies at the national and regional levels; and

4. National cooperation and coordination fails: Parties are unable to forge operational synergies at the national level due to lack of enabling policy, capacity or mandate disagreements between ministries (e.g. lack of communication and institutional structures that can facilitate regularized coordination). Implementation of synergies actions fails.

In this case, Goal (e) of 'protecting human health and the environment for the promotion of sustainable development' is intended to result from 'strengthening the implementation of the three conventions at national, regional and global level', that is, changes in third-party behaviours within countries acting in compliance with national regulatory requirements that stem from Convention provisions. Although reducing threats to human health through the convention mechanisms features in 
the overall goal, it would be unrealistic to attempt to measure the downstream effects of changed management arrangements in Convention Secretariats at that level.The locus for measuring performance in the normative work, in this situation, is not feasible at the level of changes in environmental status/condition, because the causal linkages are indirect and weak and so any observed effects are difficult to attribute to the upstream change in question. This implies that evaluation of the effects of the synergies decisions are best captured at the outcome level and viewed as contributions to higher-level intended objectives.

\section{The Global Environment Facility joint geothermal imaging project}

The evaluation of the Joint Geothermal Imaging project and a follow-up study undertaken by the Global Environment Facility (GEF) Evaluation Office made use of Theory of Change and provided another example of normative research work the development of ways to combine data from different imaging methods for site identification of geothermal wells. The potential to establish linkages between site identification and environmental benefits in terms of $\mathrm{CO}_{2}$ emissions avoided was identified during the Terminal Evaluation ${ }^{7}$ of the project, and UNEP developed the Theory of Change as a contribution to the follow-up study undertaken by the GEF Evaluation Office. The Theory of Change shows the pathways from imaging method development, scientific capacity-building and training events (often considered as normative activities) through to the resulting benefits expressed as $\mathrm{CO}_{2}$ equivalents avoided from the use of geothermal electricity generation (rather than the 'business as usual' scenario, which would have resulted in fossil fuel $\mathrm{CO}_{2}$ emissions) (see Figure 9.4).

The points to note in this example are that many development projects contain normative aspects, and it is not unusual for the causal pathways from project activities to the desired development objectives to be somewhat indirect. In this case, tracing the actual results of the project along the causal pathways leading towards the intended objectives highlighted the fact that the application of the imaging technology could be linked to quantifiable improvements in energy-generating efficiency of geothermal wells, which can be expressed in terms of $\mathrm{CO}_{2}$ emissions avoided. Routine application of Theory of Change approaches can aid in identifying projects that have potential for more detailed impact evaluations, because causal pathways that may have high 'attributive ease' can be identified.

\section{Forest certification: normative work leading to quantified benefits through a regulatory framework}

Forest certification provides an example of an evaluation - using Theory of Change as a guiding framework - of normative work on improving the criteria and indicators used for assessment and certification of sustainable forest management through scientific testing. An example of a previous evaluation ${ }^{8}$ has applications for several UNEP projects, including one UNEP-Global Environment Facility (GEF) project ${ }^{9}$ 
OBJECTIVES: Increased development of geothermal energy in place of diesel generation. Geothermal energy becomes a preferred choice in diversification of baseload power capacity, particularly in drought prone areas.

Ultimate Project Contributions Reduced $\mathrm{CO}_{2}$ emission in Kenya and later in other East African countries (Great Rift Valley)

\section{Ultimate Project Contributions} Increased proportion of drilling, investment, efficiency and competitiveness of geothermal electricity production in Kenya, expanding also outside Olkaria

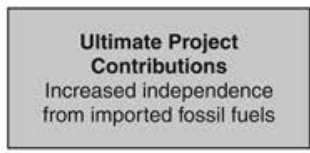

Assumptions

Petroleum prices continually high in order to justify geothermal

Expanded adoption of geothermal initiatives in neighboring countries

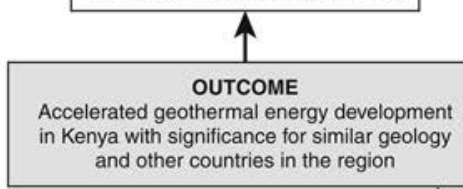

Impact driver

Development of a national strategy for involvement of multilateral, national and IPPS

(private sector agencies) in geothermal energy investment in the region

Impact Driver

Local technicians that

have received JGI

training are remunerated

sufficiently well to remain

working in geothermal

units at KenGen
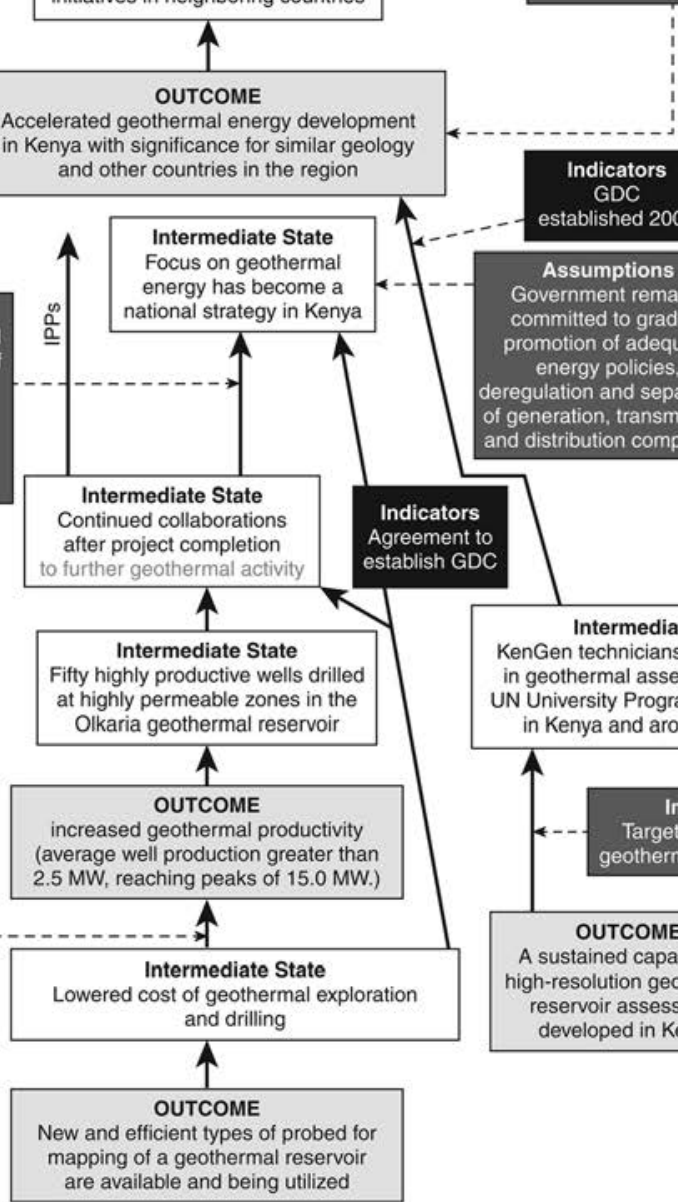

\section{Intermediate State}

KenGen technicians provide training in geothermal assessment through UN University Programs and Courses in Kenya and around the world

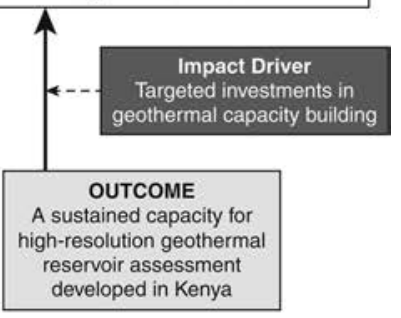

\section{ABBREVIATIONS}

KenGen = Kenya Electricity Generating Company

GDC = Geothermal Development Company (GoK) ARGeo = African Rift Geothermal Energy Project (GEF)

KETRACO = Kenya Electricity Transmission Company Ltd.

FIGURE 9.4 Theory of Change - Joint Geophysical Imaging Methodology for

Geothermal Reservoir Assessment 
that was a follow-up to the original Centre for International Forestry Research investigation.

The impact of research is generally more readily appraised in situations in which new science-based innovations are clearly defined and in which their adoption directly affects patterns of production, consumption and human welfare. Nevertheless, impacts from science may also be achieved indirectly, for example through influencing policies, decision-making processes, management assessment processes or development assistance strategies. When research leads to developing new technologies for use directly by land mangers (e.g. farmers/forest managers), the magnitude of the impact often depends on the number of adopters and the land areas over which the research innovation yields an improvement (i.e. a cumulative effect). However, there are other types of impact pathways in which a small number of adoption events (or even a single event) can change the way a system or a process functions, for example, national governance processes or a regulatory system (such as forest certification); more normative pathways create a systemic effect.

The research criteria and indicators for sustainable forest management generated information rather than finished technologies. However, utilizing information from research (to a greater degree than with finished technologies) is not a binary phenomenon (i.e. uptake or no uptake). The use of information from research may be symbolic, conceptual or instrumental, and often there is no straight-line cause and effect between providing information and outcomes leading towards intended environmental effects and benefits. Additionally, information may be only partially applied, further increasing the difficulties of determining the level of adoption and concomitant linkages to any changes on the ground.

The criteria and indicators for sustainable forest management developed through the Centre for International Forestry Research analysis were intended to be of relevance for application at individual Forest Management Units to improve forest management across a wide range of countries and settings. The criteria and indicators were also intended to have relevance for broader forest-related initiatives at both national and regional levels. Although the criteria and indicators were intended for application at the Forest Management Unit level, a range of pathways leading to improved forest management were anticipated. In fact, achieving the desired outcomes of widespread improvement in forest management at the Forest Management Unit level was thought to be less likely through a series of independent, direct (and cumulative) adoption events among multiple, separate and widely geographically dispersed forest management entities. Widespread impact was thought to be more likely to occur through using criteria and indicators in regulatory processes (e.g. national legislation and regulation and voluntary certification) (see Figure 9.5).

The uptake (and impact) strategy for the criteria and indicators work was based on the premise that collaborative research and engagement of key stakeholders would effectively generate interest in, and ownership of, the research findings among key user groups. It was anticipated that the work would be used by forest certification bodies, accreditation agencies, development assistance agencies, national forestry 


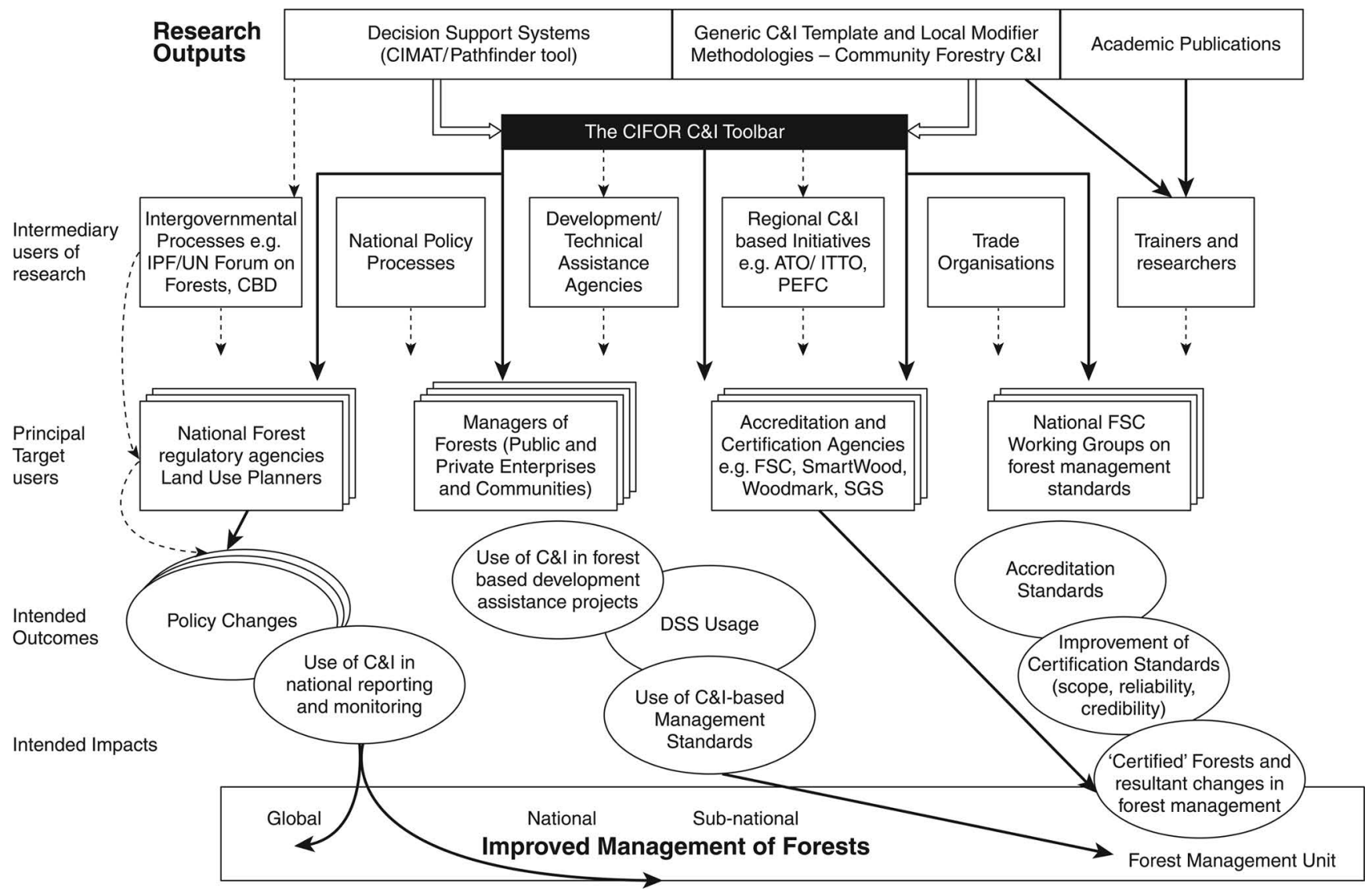

FIGURE 9.5 A Generalized Representation of Impact Pathways Relating the Centre for International Forestry Research Criteria and Indicators Project. Source: Spilsbury (2005) 
authorities and regional and national criteria and indicators development processes in order to help assimilate current best practices. The research also helped to orient existing criteria and indicators-related trends and initiatives in the right direction.

In the detailed evaluation of this project, ${ }^{10}$ evidence of causal changes was traced along multiple pathways in the Theory of Change. However, the pathways that passed through certification processes presented an opportunity to link uptake (by certification bodies into their certification standards) of the normative research to changes in management practices in certified forests through the regulatory chain of independent certification audits that applied the revised standards to different forest management enterprises across the world (see Figure 9.6).

It is possible to examine the causal effects of Forest Stewardship Council certification in terms of changes to on the ground forest management by examining the specific improvements in forest management that forest owners/managers were

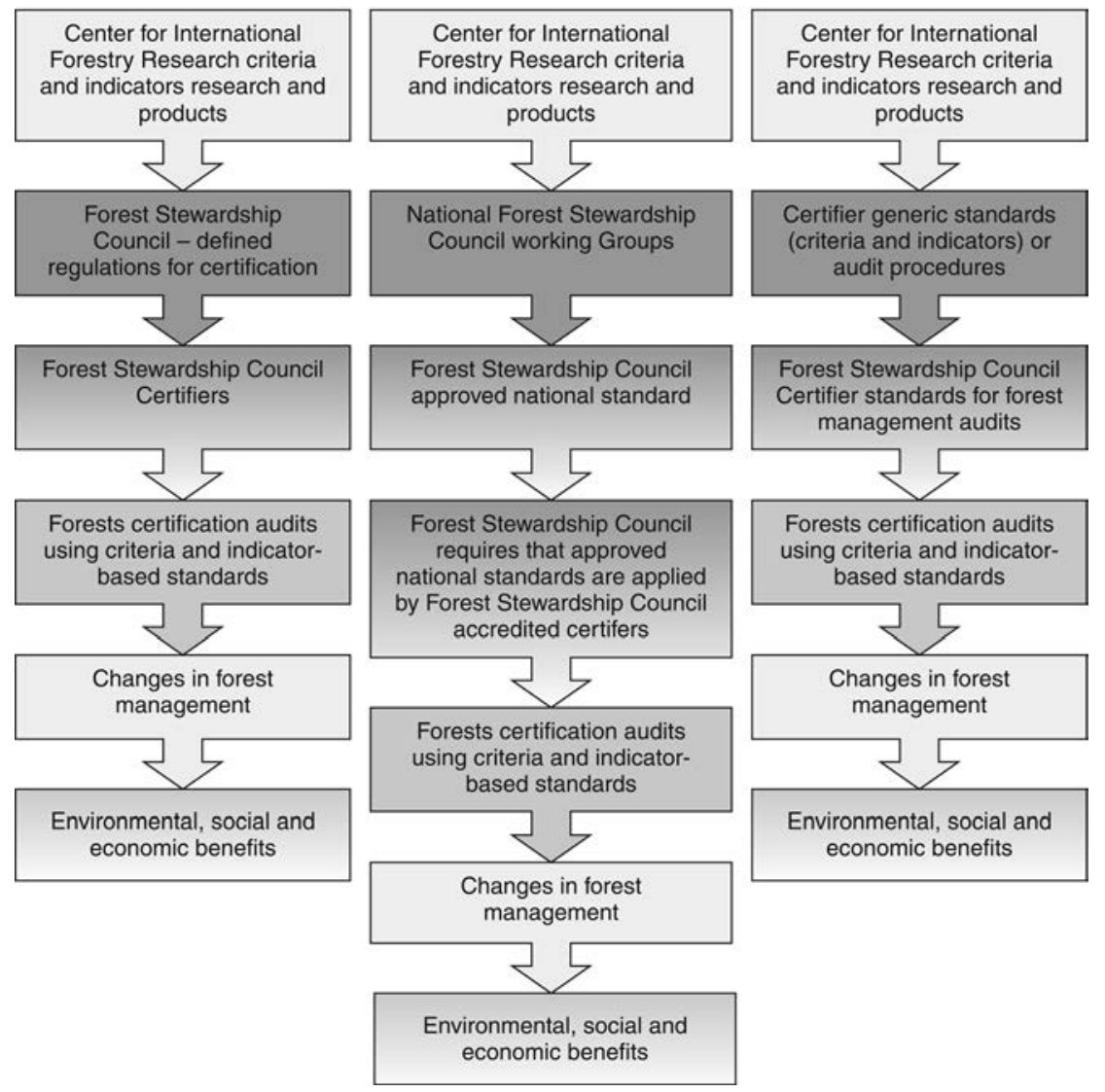

FIGURE 9.6 Major Impact Pathways through Forest Stewardship Council Certification Processes. Source: Spilsbury (2005) 
required to make in response to the certification auditing process. These provide a means of examining before-and-after situations in certified forests.

The Forest Stewardship Council forest certification audit process requires independent third-party certifiers to assess forest management against consistent criteria and indicators-based standards, highlighting which management aspects are in compliance and, critically, where standards are not met.

Non-compliance with the certifier's standards or failure to adequately meet the certification standard's forest management performance criteria results in the issuance of a corrective action requests, which outline what needs to be improved in order to bring the operation into compliance. Corrective action requests are specified in publicly available Certification Assessment Reports ${ }^{11,12}$ and define aspects such as forest production, environmental, social and economic issues the operation is required to address in order to attain certification.

The certification regulatory system, which includes follow up audits, ensures that forest management entities improve their management with regard to these corrective action requests in order to become compliant and receive or retain their official certified status. Thus, any forest management entity that achieves a certified status must have successfully addressed any corrective action requests that were issued during the certification process. If the corrective action requests are checked against, and correspond to, the specific criteria and indicators in the new standards that the research work improved, then a credible causal link between normative research and changes in the on the ground management of multiple forest enterprises that have been certified can be established. Early identification of causal pathways through Theory of Change analysis during project design and implementation proved invaluable in identifying possibilities for robust evaluation.

\section{Programme theory and results-based monitoring and evaluation}

Results-based monitoring and evaluation systems are designed to address the 'so what' question in project or programme implementation. A results-based system provides feedback on the actual outcomes and goals of organizational interventions. 'Results-based monitoring is a continuous process of collecting and analyzing information to compare how well a project, program, or policy is being implemented against expected results' (Kusek and Rist 2004: 16). Key elements of results monitoring include collecting the baseline information that describes the existing situation before the intervention, defining outcome indicators, collecting information on outputs and intermediate states (or milestones) to determine if they contribute to achieving outcomes, systematic quantitative and qualitative reporting on progress made towards achieving outcomes, collecting information on stakeholder perceptions and collecting information regarding the success of the partnership strategy adopted. Results-based monitoring and evaluation is often undertaken collaboratively with strategic partners.

A critical point to note is that monitoring and evaluation of development interventions can be meaningfully undertaken only when the interventions' intended 
outcomes are stated as explicitly as possible. The explicit statement of outcomes becomes the key to developing appropriate indicators that measure success because the outcomes will ultimately lead, particularly in the case of UNEP, to environmental benefits. Developing a system to monitor and evaluate development interventions is essentially 'a deductive process in which inputs, activities, and outputs are all derived and flow from the setting of outcomes; indicators, baselines, and targets, all crucial elements of the performance framework, are derived from and based on the setting of outcomes' (Kusek and Rist 2004: 57).

Within UNEP's planning framework, project activities are designed to deliver certain outputs that are intended to lead to certain predefined results, which are expected to contribute to the expected accomplishments (immediate outcomes). Within project-, programme framework- and sub-programme strategy documents, the intervention logic is captured both in logical frameworks and project narratives. As many projects within UNEP's larger organizational work plans have a normative nature, applying the Theory of Change approach to evaluating higher programmatic levels is instructive and reveals a number of strategically significant findings. A Formative Evaluation of the UNEP Programme of Work 2010-2011 (UNEP 2011) analysed the causal relationships embedded in all UNEP planning documents that contributed to the Programme of Work in order to understand whether project designs were optimally linked to higher-level results. Such feedback was aimed at inducing adaptations to programme implementation in order to enhance the likelihood of success in achieving the intended results and to improve future UNEP work planning processes.

The evaluation noted that performance indicators for outcomes are normally defined within project documents. Projects, however, are often designed separately (despite efforts to promote greater collaborative design). Project-specific outcome indicators, even among sets of closely linked projects within a programme, usually have quite different metrics (depicted by tinted triangles in Figure 9.7), and outcomes often cannot be aggregated.This poses challenges for assessing aggregate performance at the level of programmatic outcomes. Programmatic outcomes are often more broadly defined outcome statements in higher-level planning documents than project-specific outcomes. In many organizations, including UNEP, higher-level planning processes are 'top down' in the sense that they derive the higher-level results statements from official mandates of governing bodies and longer-term programmatic strategies. In effect, programmatic outcomes define a 'set' or category intended to encompass several project-specific outcomes. Most organizations face challenges in both monitoring and evaluating performance at this level.

Analysis of Theories of Change at higher organizational levels shows that programme designs can contain inherent weaknesses that pose problems. For example, in UNEP's Programme of Work 2010-2011, outcome indicators were not suitable for assessing performance across the contributing projects. In addition, there were often temporal problems in using such indicators to monitor progress in programme implementation. It was often the case that achieving project-level outcomes was neither linear nor incremental. Outcomes of normative international work may frequently involve a change in national policies that are discrete events, not ones that 


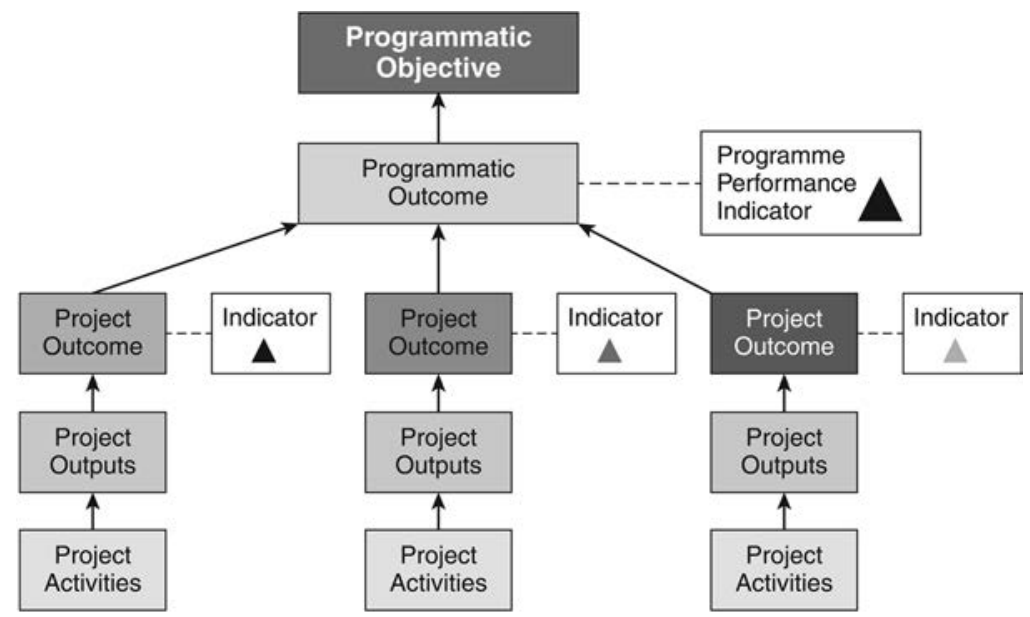

\section{Project outcomes often differ and cannot be aggregated (i.e. it is not possible to add $\Delta+\Delta+\Delta)$. \\ If performance is monitored at Programme level using only one indicator e.g. $\mathbf{\Delta}-$ there is a potential loss of accountability for the other projects}

FIGURE 9.7 Theory of Change - Common Problems in Capturing Performance at the Programme Level

gradually accrue over time. Monitoring such outcomes would repeatedly record 'no change' until such time as a policy change occurred - often anticipated towards the end of (or considerably beyond) project implementation.

The utility of directing highly aggregated monitoring information as results-based feedback into lower level management processes is extremely limited. Monitoring should focus on verifiable milestones that chart progress towards desired result levels. Milestones capture progress from project initiation to achievement of outcomes, and should be specified as activities, sub-outputs needed to deliver key outputs, the key outputs themselves or activities or events needed to ensure that outputs lead to outcomes. Milestones will usually be closely linked to the outputs and impact drivers identified in a Theory of Change and should be activities or deliverables for which clear accountability can be specified.

This is the crux of results-based management - the interface between sound causal logic, results frames and individual accountabilities within organizational management structures. Organizations can aspire to achieve outcomes (and the benefits that stem from them). However, individuals within an organization cannot be held directly accountable for outcome achievement. An outcome involves a change in behaviour beyond the direct control of a project or intervention. Thus, individuals cannot reasonably be held accountable for a change in someone else's behaviour, although they can (and should) be held accountable for doing all the things that are necessary and feasible to maximize the likelihood that an outcome will be achieved. These activities should form a standard component of work planning and performance appraisal. For example, though UNEP projects cannot be 
held directly accountable for the promulgation and implementation of national climate change policies, they can facilitate policy development processes by presenting workshops, providing technical support, ensuring the engagement of relevant government institutions and civil society in policy processes, enabling access to good practice examples and fostering of high levels of ownership.

Project milestones should be used to track the progress of project implementation through outputs and onwards to outcomes to immediate objectives. The Formative Evaluation of the UNEP Programme of Work 2010-2011 (UNEP 2011) found that the overwhelming majority of project milestones in approved project documents were pitched at or below the output level. In a few cases, milestones referred to external events that would have happened anyway. Very few milestones captured processes and achievements further along the intended causal pathways towards higher-level results in the organization's Medium-Term Strategy.

\section{Evaluating the cost-effectiveness of normative work}

Although it is possible to track progress towards achieving outcomes and impacts through theory-based approaches, one of the more problematic evaluative issues in normative work is how to determine cost-effectiveness. Often, donors and governments are unsatisfied with the simple answer that outcomes have been achieved. Invariably, they seek an answer as to whether the intervention represents value for money. Determining value for money involves analysing cost-effectiveness, which should measure the cost of achieving intended programme outcomes and impacts and should compare the costs of alternative ways of producing the same or similar benefits.

In general, although it may be feasible to document programme or project costs, estimating the environmental and other benefits further along the results chain often presents a much more complex problem and is seldom attempted. Environmental benefits stemming from project outcomes are less amenable to measurement because they are often not easily quantifiable and are frequently only partially attributable to the intervention. Comparing alternative ways of producing the same or similar benefits involves benchmarking for which data are frequently unavailable. For normative environmental work, therefore, the difficulties related to determining outcomes and impacts that occur further along the results chain (as well as attribution issues) make cost-effectiveness analysis at that level an almost intractable exercise.

Given the difficulties associated with undertaking cost-effectiveness analysis within the context of limited evaluation resources, the authors are of the view that initiating any effort to determine value for money for development interventions of a normative nature, especially as it relates to environmental activities, should focus on assessing cost-efficiency. Cost-efficiency relates to how well inputs are converted to outputs. Expected benefits should be set out along the results chain found in well-prepared logframes and causal pathway/Theory of Change analysis. Outputs (and sometimes outcomes) are often clearly defined in planning documents and their achievement is often better documented and more readily verifiable. 


\section{Conclusion}

Our experience from evaluations of a wide range of environmental activities leads us to conclude that the causal logic that undergirds the theory-based approach provides a robust method for understanding development interventions and facilitates the evaluator's ability to clearly map progress towards the results of development interventions. Although the approach does not guarantee that impacts can be readily identified and irrefutably attributed to particular development interventions, it nevertheless facilitates contribution analysis and the identification of impact drivers and intermediate states that, from both a planning and adaptive management perspective, can increase the likelihood of attaining impacts. From an evaluative perspective, such approaches increase the clarity and rigour of assessments. Contrary to some commonly expressed views in the evaluation community, we see no clear differences in methods used to evaluate normative as opposed to operational activities. Normative interventions do not define a separate category but are part of a continuum from very indirect to more direct (on the ground) interventions. The differences relate to the relative lengths/complexities of the causal pathways to impact with associated attribution issues.

The bulk of the work undertaken in UNEP has a normative character, and hence the various causal pathways to ultimate impact are often quite long - which presents challenges for assessing ultimate impacts. Theory of Change analysis, however, improves the clarity of evaluative analysis with regard to achieving the immediate outcomes and their causally linked intermediate states in order to enhance the analysis of performance.

It is our view that because project logical frameworks do not often provide comprehensive information on the processes by which project outputs yield outcomes and eventually lead, via intermediate states, to impacts, causal pathways need to be carefully examined and the following questions addressed:

- Are there other causal pathways that would stem from the use of project outputs by other potential user groups?

- Is each pathway complete? Are there any missing intermediate states between project outcomes and expected accomplishments?

- Have the key impact drivers and assumptions been identified for each step in the pathway?

Our experience shows that it is possible, within a programmatic framework, for an evaluation to map the causal pathways for sets of related projects in order to clarify how projects intend to deliver project outputs, achieve outcomes and contribute to higher-level results. Within the context of evaluations, a Theory of Change approach can provide the conceptual framework for detailing the relationship among explicit (planned) and implicit outcomes and impacts or to set clear targets and reconstruct indicators of success where they are not readily available. The analysis can identify whether interventions, by design, are mutually reinforcing and converge and 
synergize with one another to deliver the intended higher-level results. At the same time, the analysis can highlight possible interlinkages between related programmes. The approach is sufficiently flexible to incorporate analysis of causal pathways that were not foreseen in interventions' initial planning. Indeed, comparing the causal pathways from the initial project designs to the pathways that evaluative evidence highlights as being the most effective can offer insights into project/programme adaptive management processes.

The use of Theories of Change or causal pathways aids project design, implementation and evaluation by clarifying causal logic and identifying performance measures and key impact drivers. This information can also help define or refine appropriate monitoring approaches and provide feedback to help guide resultsoriented adaptive management. It is also the key guiding framework for resultsoriented evaluations.

\section{Notes}

1 See Leeuw and Vaessen (2009), Chapter 3, p. 15.

2 Adapted from Organisation for Economic Co-operation and Development (OECD) DAC (2002).

3 Logical frameworks show some variation from one agency to another - outcomes are sometimes termed 'purpose', some logical frameworks include 'immediate objectives' and 'development objective' and/or 'goal'.

4 See Decision BC.IX/10 (June 2008), RC.4/11 (October 2008), and SC.4/34 (May 2009), available at http://www.brsmeas.org/Implementation/DecisionsandDocuments/ Decisions/tabid/2616/language/en-US/Default.aspx.

5 For example, among ministries of agriculture, environment, health, industry, customs and excise and trade.

6 See Proposal from the Executive Secretary of the Basel, Rotterdam and Stockholm Conventions for the Organization of the Secretariats of the Three Conventions, December 2011.

7 See https://www.unenvironment.org/resources/terminal-project-evaluations/terminalevaluation-unep-gef-project-joint-geophysical.

8 See Spilsbury $(2005,2007)$.

9 GEF Project No. 1897, Improved Certification Schemes for Sustainable Tropical Forest Management.

10 See Spilsbury $(2005,2007))$.

11 For Public Certification Summaries, see:www.rainforest-alliance.org/programs/forestry/ smartwood/public-summary-reports.html; www.qualifor.sgs.com/home_qualifor/forest_management_certification/forest_management_reports.htm; and www.scscertified. $\mathrm{com} /$ forestry/forest_certclients.html.

\section{References}

Bamberger, M., J. Rugh and L. Mabry, Real World evaluation:Working under budget, time, data and political constraints, Thousand Oaks, CA, Sage, 2006.

Chen, H.T., Theory-driven evaluations, Thousand Oaks, CA, Sage, 1990. 
Chen H.T., Practical programme evaluation: Assessing and improving planning, implementation and effectiveness, Thousand Oaks, CA, Sage, 2005.

Cooperative for Assistance and Relief Everywhere (CARE) International UK, 'Peace building with impact: Defining theories of change', London, 2012.

Davies, R., 'Network perspectives in the evaluation of development interventions: More than a metaphor', EDAIS conference, New directions in impact assessment for development methods and practice, Manchester, UK, 2003.

German Agency for International Cooperation (GIZ) 'Systemic approaches in evaluation: Documentation of the conference on 25-26 January 2011', German Federal Ministry of Economic Cooperation and Development, 2011, available at http://www.evaluationconference.de/en/index.html, accessed August 232013.

Kusek, J. Z. and R.C. Rist, Ten steps to a results-based monitoring and evaluation system: A handbook for development practitioners, The World Bank, Washington, DC, 2004.

Leeuw, F. and J.Vaessen, 'Impact evaluations and development: NONIE (The Network of Networks on Impact Evaluation) Guidance on Impact Evaluation', 2009, available at http://siteresources. worldbank.org/EXTOED/Resources/nonie_guidance.pdf, accessed August 232013.

Mayne J. et al., Position paper on impact evaluation of CGIAR NRM research programmes: A broader view, Prepared for the NRM-Impact Community of Practice, 2012.

Organisation for Economic Co-operation and Development (OECD)/Development Assistance Committee (DAC), 'Glossary of key terms in evaluation and results based management', Paris, 2002.

Organisation for Economic Co-operation and Development (OECD) DAC, Glossary of key terms in evaluation and results based management, Paris, UNEG Task Force on Impact, 2002.

Patton, M.Q., How to use qualitative methods in evaluation, Thousand Oaks, SAGE Publications, 1987.

Spilsbury, M.J., 'The sustainability of forest management: Assessing the impact of CIFOR criteria and indicators research', CIFOR Impact Paper No 4, Bogor Indonesia, 2005, available at http:// www.cifor.cgiar.org/publications/pdf_files/Books/BSpilsbury0503.pdf, accessed May 20 2013.

Spilsbury, M.J., 'CIFOR. The sustainability of forest management: Assessing the impact of CIFOR criteria and indicators research'. In: H. Waibel and D. Zilberman, eds., International research on natural resource management: Advances in impact assessment, 217-245, Food and Agriculture Organization of the United Nations and CAB International, Rome, Italy, and Oxfordshire, UK, 2007.

Thomas, D.R., 'A general inductive approach for analyzing qualitative evaluation data', American Journal of Evaluation, 27(2): 237-246, 2006.

United Nations Environment Programme (UNEP), Formative Evaluation of the UNEP Programme of Work 2010-2011, United Nations Environment Programme, New York, 2011.

United Nations Environment Programme (UNEP) '2010-2013 medium-term strategy: Environment for development', United Nations Environment Programme, New York, 2007.

United Nations Evaluation Group (UNEG), 'UNEG handbook for conducting evaluations of normative work in the UN system' (http://unevaluation.org/document/detail/1484).

University of Kansas, 2013 Community Tool Box, 'Developing a framework or model of change', available online at http://ctb.ku.edu/en/dothework/tools_tk_4.aspx, last accessed September 112013.

Vogel, I., 'Review of the use of theory of change in international development', Review Report for UK Department of International Development (DfID), London, 2012a.

Vogel, I, 'Ecosystem Services for Poverty Alleviation (ESPA) guide to working with Theory of Change for research projects', Report for DfID, National Environment Research Council and Economic and Social Research Council, London, 2012b. 